\title{
The Pro-allergic Influences of Helminth Parasites
}

\author{
David I Pritchard
}

\author{
Department of Life Science, Nottingham NG7 2RD, UK
}

Parasitic infection is highly allergenic, and the present paper illustrates how parasites might disrupt the regulation of IgE synthesis, resulting in heightened Th-2 responses. The study of parasites, and dysregulation of the IgE ntwork, could in turn provide information relating to the aetiology of allergic diseases such as asthma and atopic dermatitis.

Key words: allergic response - helminth infection - allergen - cytokine

Helminth parasites are highly antigenic and particularly adept at exerting a pro-allergic adjuvant effect, where Th-2 lymphocytes and their cytokines (particularly, IL3, 4* and 5) promote mastocytosis, IgE synthesis and eosinophilia (Pritchard 1993a).

An increase in our understanding of the mechanisms employed by parasites to support this potentially host-protective (Pritchard et al. 1995) or parasite-protective immune response - Th-1 responses seem to be successful in controlling invasive larval stages of some parasites (Pritchard \& Wilson 1997) - would serve the dual purpose of providing: (i) a sound basis for the development of anti-parasitic immuno-therapeutic strategies; (ii) an insight into the mechanisms responsible for the development of and upsurge in allergic disease in parasite-free countries.

This article presents a brief summary of the current understanding of the factors in the immunological environment which influence T-cell development, and indicates points along this developmental pathway at which parasites and their products could influence this environment to promote allergic responses.

\section{WHY ARE HELMINTH INFECTIONS SO ALLER- GENIC?}

Helminth parasites are particularly adept at stimulating IgE synthesis, and a number of parasite allergens have recently been cloned and characterised (McReynolds et al. 1993). Do certain parasite antigens have molecular properties

Fax: +44-115-951.3251

*There is recent evidence, in mice, that class switching to IgE can be initiated by retroviral infection, using IL4 independent pathways (Morawetz et al. 1996). Helminths apparently do not use this pathway.

Received 3 September 1997

Accepted 30 September 1997 which support their allergenicity? This is a question which has puzzled immunologists for decades, and a number of theories have been put forward. One popular theory at present is based on the fact that many allergens have enzymatic activity (e.g. Der $p$ I from Dermatophagoides pteronyssinus), and that enzymatic activity somehow deviates antigen processing in a way that supports the generation of Th-2 lymphocytes. It is, therefore, of interest that highly allergenic parasites such as the schistosomes and hookworms are rich sources of secreted proteinases (Smith et al. 1994, Brown et al. 1995). How do these enzymes promote IgE synthesis? One clue to a possible mechanism comes from an observation made in a population in Papua New Guinea infected with the hookworm Necator americanus. This population was noted to have exceedingly high levels (on average, 40 times that of normal) of soluble CD23 (the low affinity receptor for IgE) and IgE in its plasma, up to 17,000 IU/ml (Pritchard et al. 1993).

This observation led to the hypothesis that parasite proteases might accelerate the natural proteolytic cleavage of CD23 from the leucocyte surface, leading to an up regulation of immediate-type hypersensitivity through the generation of soluble CD23 (a pro-allergic cytokine) and the removal of a negative feedback signal for IgE synthesis (Pritchard 1993a). IgE containing immune complexes bind to CD23, to send a feedback inhibition signal to the B cell, which reduces IgE synthesis (reviewed by Delespesse et al. 1992). Consequently, allergens which selectively cleave CD23 would theoretically be pro-allergic. It is therefore of interest that $\operatorname{Der} p$ I, a proteolytically-active allergen of the house mite D. pteronyssinus, selectively cleaves CD23 from the human B cell surface (Hewitt et al. 1995). This is the first and most convincing experimental evidence that dust mites dysregulate the IgE network by directly interfering with the control of IgE synthesis, and these observations have since been confirmed by other workers. 
This explanation may not hold for all allergens (for example, many fatty acid binding proteins (FABP)are now proven allergens** - McReynolds, et al. 1993); however, it provides an experimental basis for testing the pro-allergic activity of at least a major group of common environmental toxins. A resumé of recent developments in our understanding of the development of helper $\mathrm{T}$ cell at this point would help to indicate other points in the development processes where parasites and their products could exert influence on Th-2 bias.

\section{RECENT DEVELOPMENTS IN OUR UNDERSTAND- ING OF T CELL MATURATION}

The early cytokine milieu seems to be of critical importance to the differential development of T cells. Both Th1 and Th 2 cells can develop from the same T cell precursor, with IL12 from macrophages and activated dendritic cells the predominant Th1 promoting cytokine, and IL4 and IL13, possibly from basophils (Ochensberger et al. 1996), $\mathrm{T}$ cells themselves or $\mathrm{CD} 4^{+} \mathrm{NK} 1.1^{+}$, equivalents in man***, promoting Th2 development. The downstream effects of these cytokines on further $\mathrm{T}$ cell development would appear to be mediated through a number of transcription factors belonging to the stat family. Of these, stat 4 would appear to be activated by IL12 (with IFN $\gamma$ playing a supportive role), and stat 6 would appear to be activated by IL4 (Kaplan et al. 1996 a,b). The other points in T cell development in which parasite products would be active are illustrated (Fig.) and described below.

The CD23 effect described would be largely mediated through B cells committed to IgE synthesis and it has already been suggested that helminths parasites may promote their own survival by stimulating polyclonal IgE synthesis, although formal proof for this hypothesis is still to be found. As well as cleaving CD23 to promote IgE synthesis, it is also possible that parasitic helminths secrete molecules which act as pseudocytokines, to maintain the Th-2 bias. Molecules with the activities of IL4, IL10 and SCD23 would fulfil these criteria.

Alternatively, if $\mathrm{Th}-2$ responses, in a specific sense, begin to damage the parasite, as has been in-

\footnotetext{
**Given the ability of FABP's to sequester vitamins, and the fact that some vitamins (e.g. D3) promote Th-2 development (Rook et al. 1994), it is possible that some allergens promote the allergic response through selective vitamin uptake.

***There is also data to suggest that $\mathrm{NK} 1.1^{+} \mathrm{T}$ cells are not involved in the triggering of Th2 responses (Brown et al. 1996).
}

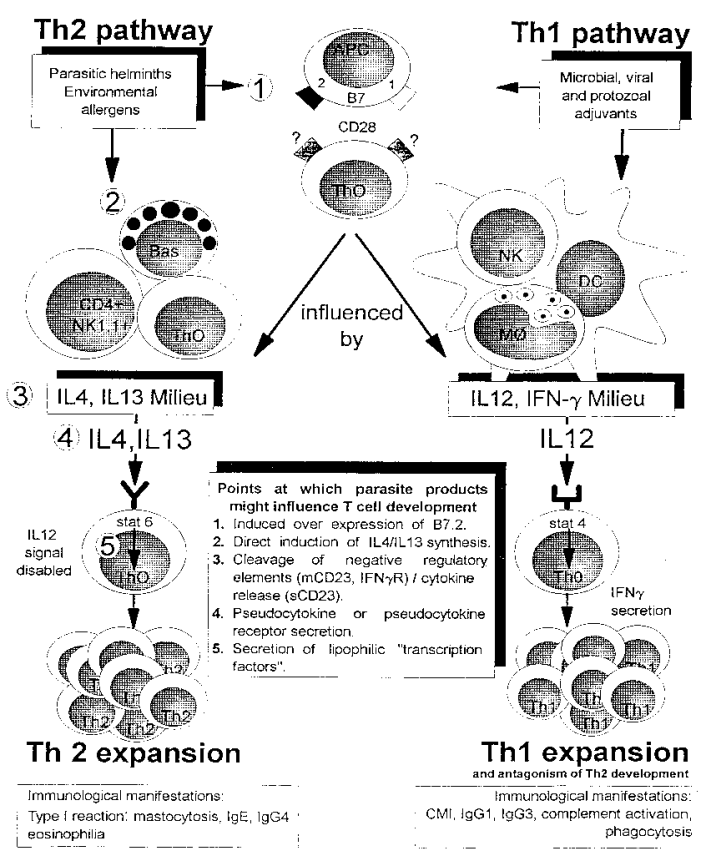

T cell development can be influenced by a number of factors in the immunological environment, and the points in T cell development where parasitic helminths and their ES products could conceivably exert an influence are shown here. For example, it is possible that helminth excretory/secretory products, particularly secreted proteinases and proteinase inhibitors (doubling as anticoagulants?), could influence the proteinase-rich antigen processing milieu to an extent that a pathway favouring Th-2 development is favoured. The mechanism by which CD28 controls IgE synthesis is sketchy. Some data supports a positive role for CD28 (King et al. 1996) through an interaction with the B7 marker (Corry et al. 1994), but it may not always stimulate through B7 (Life et al. 1995). Other data suggests that costimulation of T cells via CD28 inhibits IgE production (Van der Pouwkraan et al. 1996). Interestingly, the latter effect was reversed by pertussis toxin.

Proteinases could also effect IL4 secretion directly, in a nonantigenic fashion, in a manner similar to that already described for other enzymatically active allergens. It is also already known that another proteolytically active environmental allergen (Der $p \mathrm{I}$ ) has the ability to dysregulate the IgE network; formal proof demonstrating a similar effect by helminth proteases is lacking, although the suggestion that they might potentiate $\operatorname{IgE}$ synthesis by cleaving molecules such as CD23 was first muted in the early 90's (Pritchard 1993a).

The pro Th-2 developmental pathway would then be propagated by the possible release of cytokines (IL4, sCD23) or secretion of pseudocytokines or pseudocytokine receptors (e.g. IFN- $\gamma$ R) and even lipophilic homoserine lactones similar to those already shown to be active in chemical communication between bacteria (Williams 1994).

Another parasite secretion with the potential to modulate T cell development is acetylcholinesterase. Cholinergic influences on $\mathrm{T}$ cell development/activation have been recorded, yet it remains to be established whether extraneous sources of AChE, which would compete with $\mathrm{T}$ cell membrane AChE, exert any polarising effect on T cell development (Pritchard 1993b).

Abbreviations: APC: antigen presenting cell; BAS: basophil; DC: dendritic cell; ES: excretory/secretory product; MO: macrophage; NK: natural killer; Th0: undifferentiated T cell; STAT: signal transducer and activator of transcription; For further details of the downstream effects of IL4 on T cell development, (Anderson \& Coyle 1994, Abbas et al. 1996). 
ferred from a number of field studies described above, then it would be in the interest of the parasite to induce a Th-1 bias. This could be done through the secretion of Th-1 promoting pseudocytokines such as IFN- $\gamma$ and IL-12. This may indeed be the case in Trichuris muris infection, although the final proof regarding the activity of this pseudocytokine is lacking. Work by Birgit Helm and her colleagues (Dudler et al. 1995, Machado et al. 1996 ) would also suggest that enzymatically active allergens induce IL 4 synthesis by cells of the basophil lineage in the absence of sensitisation with IgE. This kind of direct activity would generate the early IL4 milieu necessary for Th-2 development. It is also intriguing that a number of pathogenic and non-pathogenic bacteria signal to each other through the secretion of lipophilic compounds which interact with cytosolic proteins to become transcription factors (Williams 1994). Could parasitic helminths do the same? A full list of parasite molecules with the putative ability to control $\mathrm{T}$ cell development is shown in the Table below.

TABLE

Examples of known and putative parasite secretions with the potential to support the development and growth of Th-2 lymphocytes

\begin{tabular}{ll}
\hline Excretory secretory product & Putative pro-Th-2 effect \\
\hline Proteinases e.g. cysteinyl & (i) cleavage of negative regulatory elements (CD23, IFN- $\gamma$ R/IL12R); \\
proteinases, glycosidases, & (ii) release of cytokines (sCD23) and "anti-cytokines" (sIFN- $\gamma$ R/IL12R); \\
lipases (cf. phospholipase A2) & (iii) direct induction of IL4 and IL13 synthesis \\
Proteinases/ & $\begin{array}{l}\text { Interference with cytosolic pathways of antigen processing/ } \\
\text { presentation }\end{array}$
\end{tabular}

Acetylcholinesterase

Interference with muscarinic (+ve) and nicotinic (-ve) influences on $\mathrm{T}$ cell function, and $\mathrm{T}$-cell $\mathrm{mAChE}$

Pseudocytokines/receptors/ligands Supportive of IL4 milieu, sequestration of negative regulatory cytokines. Presentation of CD40 ligand-like molecules

Superantigens

Induction of CD40 ligand expression and class switching to $\operatorname{IgE}$ (Jabara \& Geha 1996)

Mitogens

Protein kinases

Expansion of IL4-receptive B (as found in "Ascaris" body fluid) and T cell sub-populations (Lee 1995)

Lipophilic "transcription factors"

Deviation of developmental pathways to Th-2 via intracellular signalling processes

Conversion of cytosolic regulating proteins into transcription factors

\section{ACKNOWLEDGEMENTS}

To Barbara Williams for her excellent secretarial support over the years, to the Wellcome Trust for their generous and consistent financial support and to Ms Mari Nowell for the artwork.

\section{REFERENCES}

Abbas AK, Murphy KM, Sher A 1996. Functional diversity of helper T lymphocytes. Nature 383: 787-793.

Anderson GP, Coyle AJ 1994. $\mathrm{T}_{\mathrm{H}} 2$ and " $\mathrm{T}_{\mathrm{H}} 2$ - like" cells in allergy and asthma: pharmcological perspectives. TiPs 15: 324-332.

Brown A et al. 1995. An initial characterisation of the proteolytic enzymes secreted by the adult stage of the human hookworm Necator americanus. Parasitology 110: 555-563.

Brown DR, Fowell DJ, Corry DB, Dynn TA, Moskoquitz NH, Cheever AW, Locksley RM, Reiner SL 1996. $B_{2}$ microglobulin independent $\mathrm{NK} 1.1^{+} \mathrm{T}$ cells are not essential for $\mathrm{T}$ helper cell and immune responses.
J Exp Med 184: 1295-1304.

Corry DB, Reiner SL, Linsley PS, Locksley RM 1994. Differential effects of blockage of CD28 - B7 on the development of Th1 and Th2 effector cells in experimental leishmaniasis. J Immunol 153: 4142-4148.

Delespesse $\mathrm{G}$ et al. 1992. The low affinity receptor for IgE. Imm Review 125: 77-97.

Dudler T, Cantarelli-Machado D, Kolbe L, Annand RR, Rhodes N, Gelb MH, Koelsch E, Suter M, Helm BA 1995. A link between catalytic activity, IgE-independent mast cell activation, and allergenicity of bee venom phospholipase $A_{2}$. J Immunol 155: 2605-2613.

Hewitt CRA, Brown A, Pritchard DI 1995. A major house dust mite allergen disrupts the immunoglobulin E network by selectively cleaving CD23: innate protection by antiproteases. J Exp Med 182: 1537-1544.

Jabara HH, Geha RS 1996. The superantigen toxic shock syndrome toxin 1 induces CD40 ligand expression and modulates $\mathrm{IgE}$ isotype switching. Intern Immunol 10: 1503-1510.

Kaplan M., Schindle, U, Smiley ST, Grusby MJ 1996. 
Stat 6 is required for mediating responses to IL-4 and for the development of $\mathrm{Th} 2$ cells. Immunity 4 : 313-319.

Kaplan MH, Sun Ya-Lin, Hoey T, Grusby MJ 1996. Impaired IL-12 responses and enhanced development of Th2 cells in Stat 4 - deficient mice. Nature 382: 174-177.

King CL, Xianli J, June CH, Abe R, Lee KP 1996. CD28 deficient mice generate an impaired $\mathrm{Th} 2$ response to "Schistosoma mansoni" infection. Eur J Immunol 26: 2448-2455.

Lee TDG 1995. IgE regulation by nematodes: The body fluid of "Ascaris" contains a B cell mitogen. $\mathrm{J} \mathrm{Al}$ lergy Clin Immunol 95: 1246-1254.

Life P, Aubry JP, Estoppey S, Schnuriger V, Bonneyfoy JY 1995. CD28 functions as an adhesion molecule and is involved in the regulation of human IgE synthesis. Eur J Immunol 25: 333-339.

Machado DC, Horton D, Harrop R, Peachell PT, Helm BA 1996. Potential allergens stimulate the release of mediators of the allergic response from cells of mast cell lineage in the absence of sensitisation with antigen-specific IgE. Eur J Immunol 26: 2972-2980.

McReynolds LA, Kennedy MW, Selkirk ME 1993. The polyprotein allergens of nematodes. Parasitol Today 9: 403-406.

Morawetz RA, Gabriele L, Rizzo IV, Nobentrauth N, Kuhn R, Rajewsky K, Muller W, Doherty TM, Finkelman F, Coffmann RL, Morse HC 1996. Interleukin (IL)4 - independent immunoglobulin class switch to immunoglobulin (Ig) E in the mouse. J Ex Med 184: 1651-1661.
Ochensberger B, Daepp GC, Rihs S, Dahunden CA 1996. Human blood basophils produce interleukin 13 in response to $\mathrm{IgE}$ receptor dependent and independent activation. Blood 88: 3028-3037.

Pritchard DI, Kumar S, Edmonds P 1993. Solubles(s) CD23 levels in the plasma of a parasitized population from Papua New Guinea. Parasite Immunol 15: 205-208.

Pritchard DI 1993a. Immunity to helminths: is too much IgE parasite - rather than host-protective? Parasite Immunol 15: 5-9.

Pritchard DI 1993b. Why do some parasites need to secrete acetylcholinesterase (AChE)? International J Parasitol 3: 549.

Pritchard DI, Quinnell RJ, Walsh EA 1995. Immunity in humans to Necator americanus: IgE, parasite weight and fecundity. Parasite Immunol 17: 71-75.

Pritchard DI, Wilson RA 1997. Helminth infections. In Robert A Stockley, Pulmonary Defences. John Wiley and Sons Ltd.

Rook GAW et al. 1994. Hormones, peripherally activated prohormones and regulation of the Th1/Th2 balance. Immunol Today 15: 301-303.

Smith AM et al. 1994. Adult Schistosoma mansoni express cathepsin L proteinase activity. Mol Bioch Parasitol 67: 11-19.

Van der Pouwkraan CTM, Rensink HJAM, Rappuoli R, Aarden LA 1996. Co-stimulation of T cells via CD28 inhibits human IgE production; reversal by pertussis toxin. J Clin Exper Immunol 99: 473-478.

Williams P 1994. Compromising bacterial communication skills. J Pharm Pharamacol 46: 252-260. 